\title{
STUDY OF GRANULAR GELS PROPERTIES TO CONTROL THE DEVELOPMENT OF OIL FIELDS
}

• . вчинников , . ли

S. V. Ovchinnikova, G. H. Ali

юменский индустри льный университет, г. юмень

\author{
лючевые слов : тест дин мической фильтр ции; н бух ние поли крил мид; \\ нефтяные месторождения \\ Key words: dynamic filtration test; swelling polyacrylamide; mature oil fields
}

уществует дв ст нд ртных тест н обр зц х керн для оценки эффект от гр нулиров нного геля. ест ст тической фильтр ции и тест дин мической фильтp ции. ест ст тической фильтр ции предн зн чен для тестиров ния 3 к чки в м трицу породы, тогд к к тест дин мический фильтр ции подходит для оценки 3 К чки в трещину. ест фильтр ции позволяет прояснить процессы и явления, которые определяют приемистость PPG в низкопрониц емых пл ст х или влияют н нее. к честве н гнет тельной жидкости использов ли $\mathrm{p}$ ссол $\mathrm{p}$ зличной концентр ции.

рониц емость р зличных обр зцов песч ник измеряли до и после воздействия гелем, т к же измеряли прониц емость с мого геля. зменяли д вление 3 к чки и концентр цию р ссол, чтобы определить ее влияние н прочность геля и н продуктивный пл ст. т р бот позволил определить, д ет ли гель ус дку при вз имодействии с обр зц ми песч ник низкой прониц емости. стицы геля должны блокиров ть зону с высокой прониц емостью, позволить 3 к чив емой воде войти в зону с низкой прониц емостью и т ким обр зом повысить охв т пл ст $з$ воднением. ереп д д вления измеряли н д обр зцом песч ник для р счет прониц емости геля и обр зц керн после обр ботки гелем.

сновными компонент ми PPG являются: сшитые солью к лия поли крилов я кислот или сополимер поли крил мид . PPG может поглощ ть большое количество воды з счет водородной связи с молекулой воды. в вид PPG были использов ны для н ших экспериментов фильтр ции: цин k 40 (30 mesh) и k 40 (40 mesh). змеры ч стиц геля н ходятся в ди п зоне от 30 до 80 меш. стицы геля k 40 (30 mesh) - жесткие с модулем упругости более 8000 после полного н бух ния, ч стицы геля $\mathrm{k} 40$ (40 mesh) - мягкие с модулем упругости около 800 . б $\quad$ PPG при н бух нии увеличив ются в р змере до $10 \sim 100$ р з. онцентр ция р ссол зн чительно влияет н н бух ние PPG. ысок я соленость р ссол приводит к снижению коэффициент н бух ния, но прочность н бухших ч стиц выше. ля приготовления н бухшего PPG были использов ны три зн чения концентр ции солевого р створ $(0,05 ; 1$ и $10 \%)$. 
т блице 1 пок з но снижение прониц емости обр зцов керн для к ждого эксперимент с использов нием геля k 40 (40 mesh). т блице 1 б- прониц емость породы до з к чки геля, $\mathrm{K}$ - прониц емость после 3 к чки геля.

нижение прониц емости после обр ботки гелем

\begin{tabular}{|c|c|c|c|}
\hline Q (мл/мин) & К гель, мд & б гель, мд & (\%) уменьшение \\
\hline 1 & 29,84146 & $-37,6571$ & 2,261905 \\
\hline 3 & 27,42655 & 7,322211 & 0,733025 \\
\hline 5 & 27,94342 & 7,202175 & 0,742259 \\
\hline 7.5 & 23,12277 & 7,814217 & 0,662055 \\
\hline 10 & 23,15663 & 8,077618 & 0,651175 \\
\hline 15 & 25,15797 & 8,214669 & 0,673476 \\
\hline 20 & 27,19858 & 7,911944 & 0,709105 \\
\hline 25 & 29,2239 & 8,275416 & 0,716827 \\
\hline 30 & 30,55243 & 8,297993 & 0,728402 \\
\hline
\end{tabular}

рисунк х 1 и 2 пок з ны результ ты исследов ния прониц емости пород и ст билизиров нного д вления с р зным обр тным д влением $(0 ; 0,345 ; 0,690 ; 1,380$ ) после обр ботки гелем k 40 (40 mesh).

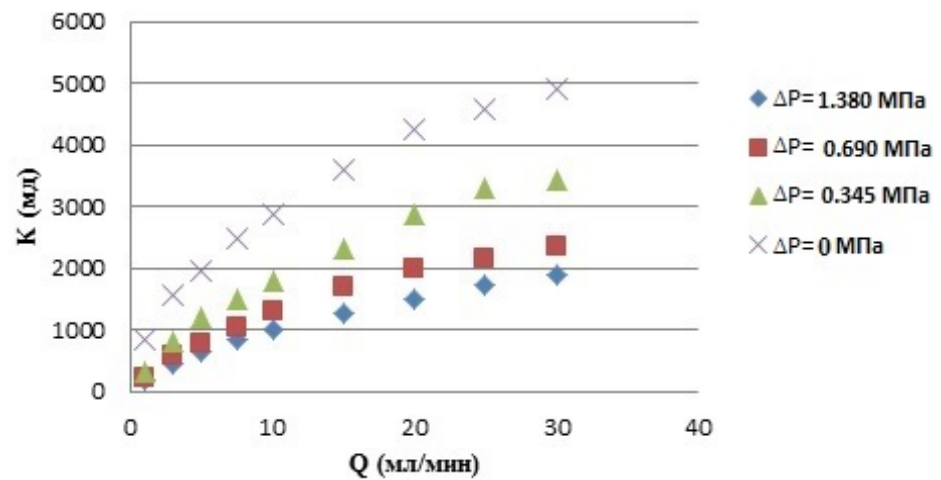

ис. 1. езульт ты исследов ния прониц емости пород с р зным обр тным д влением $(0 ; 0,345 ; 0,690 ; 1,380 \quad$ ) после обр ботки гелем $k 40$ (40 mesh)

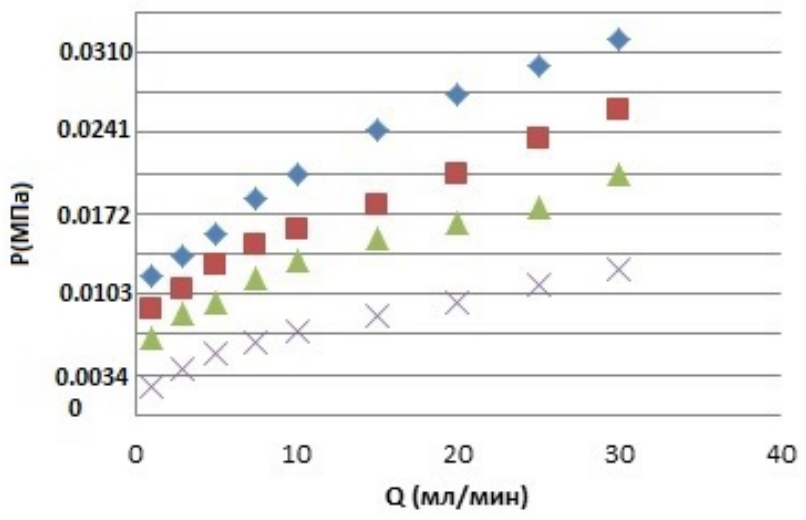

\section{$\Delta \mathrm{P}=1.380 \mathrm{M} \Pi \mathrm{a}$ \\ $\Delta \mathrm{P}=0.690 \mathrm{M} \Pi \mathrm{a}$ \\ $\Delta \mathrm{P}=0.345 \mathrm{M} \Pi \mathrm{a}$ \\ $\times \Delta \mathrm{P}=0 \mathrm{M} \Pi \mathrm{a}$}

ис. 2. езульт ты исследов ния ст билизиров нногод вления с р зным обр тным д влением $(0 ; 0,345 ; 0,690 ; 1,380 \quad)$ после обр ботки гелем $k 40$ (40 mesh) 
т блице 2 пок з но снижение прониц емости обр зцов керн для к ждого эксперимент с использов нием геля k 40 (30 mesh).

нижение пронии емости после обр ботки гелем

\begin{tabular}{|c|c|c|c|}
\hline Q (мл/мин) & К гель, мд & б гель, мд & (\%) уменьшение \\
\hline 1 & 29,84146 & 29,84146 & 0 \\
\hline 3 & 27,42655 & 27,42655 & 0 \\
\hline 5 & 27,94342 & 27,94342 & 0 \\
\hline 7,57 & 23,12277 & 23,12277 & 0 \\
\hline 10 & 23,15663 & 23,15663 & 0 \\
\hline 15 & 25,15797 & 25,15797 & 0 \\
\hline 20 & 27,19858 & 27,19858 & 0 \\
\hline 25 & 29,2239 & 29,2239 & \\
\hline 30 & 30,55243 & 30,55243 & \\
\hline
\end{tabular}

рисунк х 3 и 4 пок з ны исследов ния прониц емости пород и ст билизиров нного д вления с р зным обр тным д влением $(0 ; 0,345 ; 0,690 ; 1,380$ после обр ботки гелем k 40 (30 mesh).

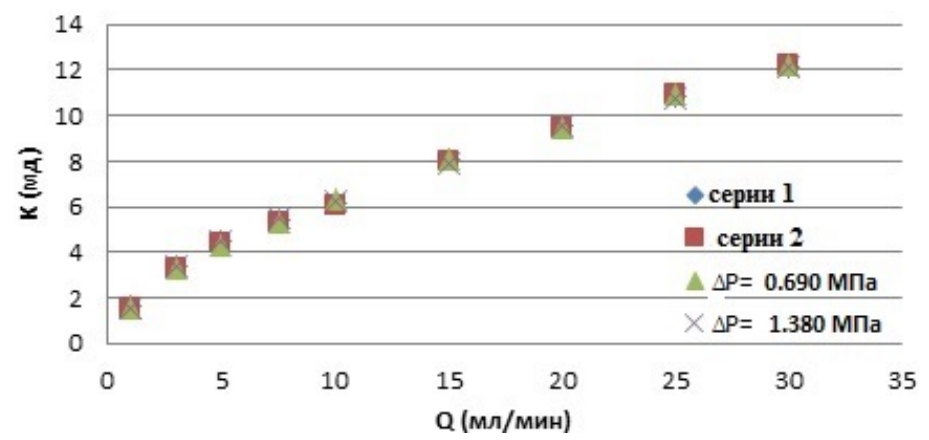

ис. 3. езульт ты исследов ния прониц емости породс р зным обр тным д влением (0; 0,345; 0,690; 1,380 ) после обр ботки гелем $k 40$ (30 mesh)

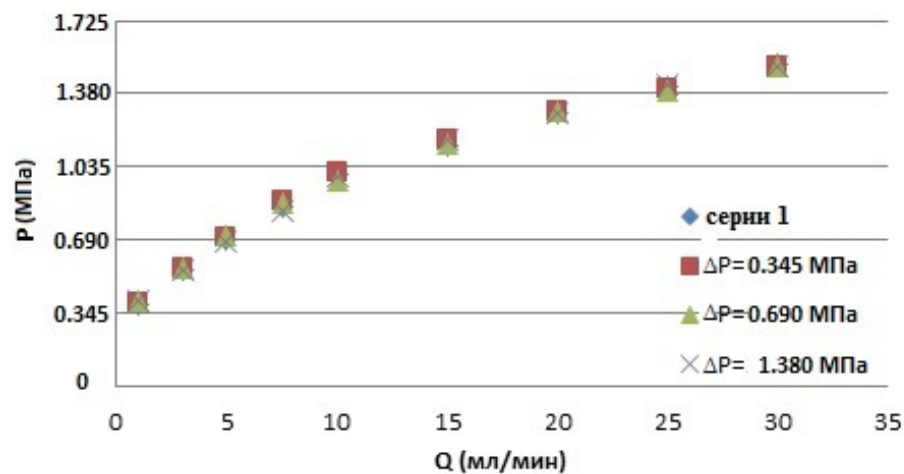

ис. 4. Результ т исследов ния ст билизиров нного д вления с р зным обр тным д влением (0; 0.345; 0.690; $1.380 \quad$ после обр ботки гелем $k 40$ (30 mesh) 
blводы

спользов ние геля К 40 (30 меш) не пн носит вред зоне с низкой прониц емостью. К 40 (40 меш) обр зует прониц емые слои н поверхности керн и уменьш ет их прониц емость.

щерб от PPG для низкопрониц емых, бог тых нефтью зон может быть эффективно предотвр щен путем регулиров ния прочности применяемого геля.

писок литер туры

1. Al-Anaza, and Sharma, M.: «Use of a pH Sensitive Polymer for Conformance Control», paper SPE 73782 presented at 2009 International Symposium andExhibition on Formation Damage Control, 20-21 February, Lafayette, Louisiana.

2. Chauveteau, G., Tabary, R., Bon, C., Renard, M., Feng, Y., and Omari, A. 2003. In-Depth Permeability Control by Adsorption of Softsize-Controlled Microgels. Paper SPE 82228 presented at the SPE European Formation Damage Conference, The Hague, The Netherlands, 13-14 May.

3. Du, Y. and Gong, J. P. in Surface Friction and Lubrication of Polymer Gels, ed. G. Biresaw and K. L.Mittal, CRC Press, Boca Raton, Florida, May 2008, ch. 11, pp.223-246.

4. Ganguly, S., Willhite, G.P., Green, D.W., and McCool, C.S. 2001. The Effect of Fluid Leakoff on Gel Placement and Gel Stability in Fractures. Paper SPE 64987 presented at SPE International Symposium on Oilfield Chemistry, Houston, Texas, 13-16 February 2001

5. Larkin, R and Creel P. Methodologies and Solutions to Remediate Inter-well Communication Problems on the SACROC CO2 EOR Project-A Case Study.paper SPE 113305 presented at 2008 SPE/DOE Improved Oil Recovery Symposium held in Tulsa, OK, 19-23 April 2008.

\section{ведения об втор}

ссн уссейн ли, спир нт кфедры " оделиров ние и упр вление процесс ми нефте2 зодобычи», юменский индустри льный универ cumem, г. юмень, e-mail: mehemet80@yahoo.com

вчинников ветл н лерьевн, к. $c . н$. доцент к федры "изнес-информ тик им те м тик », юменский индустри льный университет, г. юмень, тел. 8(3452)283047

\section{Information about the authors}

Ali G. H., postgraduate student of the Department «Modelling and management of processes of oil and gasrecovery», Industrial University of Tyumen, e-mail:mehemet80@yahoo.com

Ovchinnikova S. V., Candidate of Science in Sociology, associate professor of the chair "Businessinformatics and mathematics», Industrial University of Tyumen, phone: 8(3452)283047, e-mail: ovchinnikovasv@tsogu.ru 